\title{
A Protection Type Porthole Die with Twin Cavities for semi-Hollow Al-Profiles
}

\author{
Xuemei Huang ${ }^{1, a^{*}}$, Rurong Deng ${ }^{2, b^{*}}$ \\ 1,2Guangzhou Vocational College of Science and Technology, Guangzhou, 510550, China

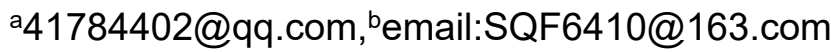

Key words: Semi-hollow, Al-profiles, twin cavities in a die, protection type, cores

Abstract. Through a common actual example, a new structure named protection type with twin cavities in a die for the semi-hollow Al-profiles was present. And the selection and the optimization of structure parameters were described in detail. the layout of die holes, the design of the portholes, the structure of the cores, the chambers and the selection of bearing belt were mainly included. It was shown that the structure with twin cavities for semi-hollow profiles is effective, the structure can greatly improve the production efficiency and reduce the cost. It is worth promoting. The purpose is to provide reliable data and reference for the further research and development of this technology on the extrusion die with multi-cavities in a die.

\section{Introduction}

Semi hollow profiles are quite common in the production of aluminum profiles extrusion. Because of high design complexity, to solve the strength is the key. And therefore, the die structure is the most important element. The traditional way is to use single cavity die. But in recent years, because the cost of the use of land, human resources and energy will continue to trend up, it is not realistic that the enterprises expand the scale of production by means of building more extrusion production line through investment or intensive manpower, the best way is to improve extrusion machine production efficiency, give full play to the potential of extrusion machine. And the die technology with multi-cavities in a die is undoubtedly one of the effective ways. the twin or a plurality of cavities is extruded in a die, the efficiency will be increased exponentially, especially in extrusion machine is equipped with a trend of large-scale, it can solve the problem that small machine has too many in order to finish, and large machine has no enough order to do. Therefore, it is very necessary and important to develop the die with twin or multi-cavities for a large variety of semi hollow sections to meet the large market demand. Through a common actual examples, a new protection type extrusion die with twin cavities will be introduced, the aim is to offer a reference to peers.

\section{Determination of Die Structure Parameters}

2.1 The Structure Form. As shown in Figure 1 for a typical semi hollow section, it is a common section of civil building doors and windows aluminum profiles.

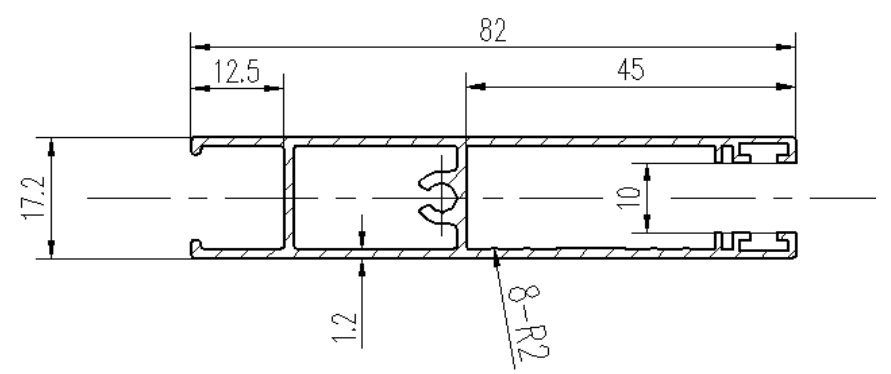

Fig. 1 The signal of the section of profile

The section of the profile is provided with a hollow part and a typical semi hollow part, the area of the section is $291 \mathrm{~mm}^{2}$, and the maximum tongue ratio of the semi hollow part is 6.5 . If the product is extruded in ordinary porthole die, the cantilever of die is very easy to break, the die life will be very short. The traditional way is to use a die with single cavity in the extrusion machine of capability from $8 \mathrm{MN}$ to $12 \mathrm{MN}$, to solve the strength of the mold, the cutting type structure of 
porthole die will be used usually. But the practice shows that it is easy to produce the phenomenon of raising wire and convex flange on the product surface. And if the cutting type structure is still used in the die of twin cavities, on the one hand, the raising wire and convex flange will also appear, on the other hand, with the increase of die cavities and the cores, the difficulty of manufacturing will greatly increase, and manufacturing error is very sensitive to the extrusion, which influence the extrusion synchronization of twin cavities, resulting in reduced efficiency and increased waste.

The protective structure, it is that a fake core will be set in the place where the strength is the weakest, in fact, the core does not enter the die hole to joint similarly to a ordinary porthole die with a clearance in the jointing part, the core is fake. When the male die and female die are assembled together, the fake core will be placed on the cantilever and keep certain gap named stress gap from the cantilever.In the extrusion process, even if the male die is bent downward by force, the fake core can not touch the cantilever, and the cantilever will be protected effectively, which improve stress state of the cantilever and reduce the force area of the cantilever, so as to greatly improve the strength of the cantilever and the die.And the fake core in manufacturing is extremely simple. The determination method of fake core size can refer to the structure of ordinary porthole die and consider the minimum resistance principle in forming of metal flow. The core size is shown in figure 2.

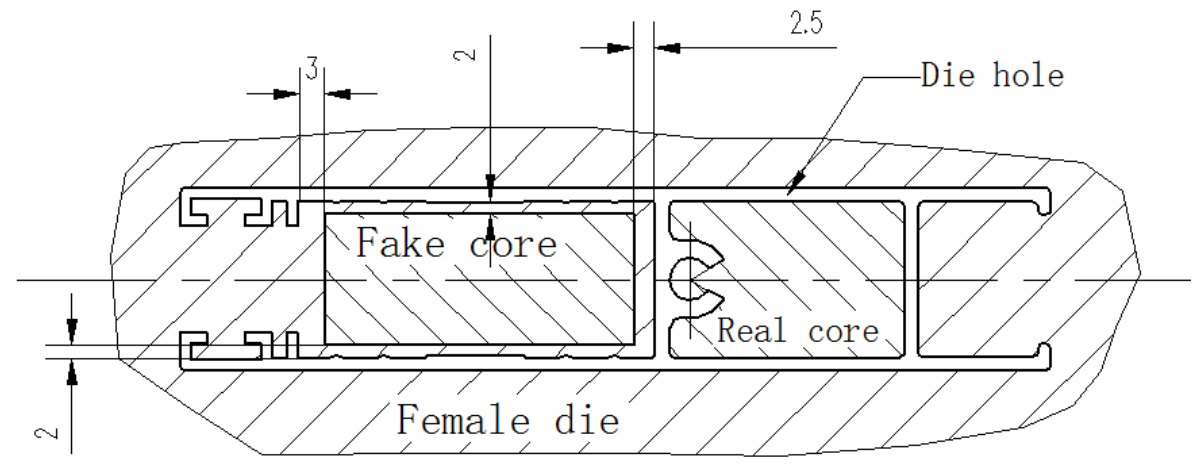

Fig.2 The signal of the fake core

The minimum distance from fake core to the cantilever opening is $3 \mathrm{~mm}$, to other die hole edge $2 \mathrm{~mm}$, and the shape of the rules must be designed as far as possible in order to facilitate processing.

2.2 The Die Holes Arrangement. According to the demand of reasonable extrusion coefficient in extrusion and saving the die cost, the extrusion machine of capability $18 \mathrm{MN}$ is selected, its inner diameter of container is $185 \mathrm{~mm}$. After calculation, extrusion pressure is $670 \mathrm{MPa}$, the extrusion coefficient of twin cavities was 46.2 , the die dimensions is diameter of $250 \mathrm{~mm}$ and thickness of 160 $\mathrm{mm}$. In this machine, the layout of the die hole can be arranged in two ways, as shown in figure 3 .

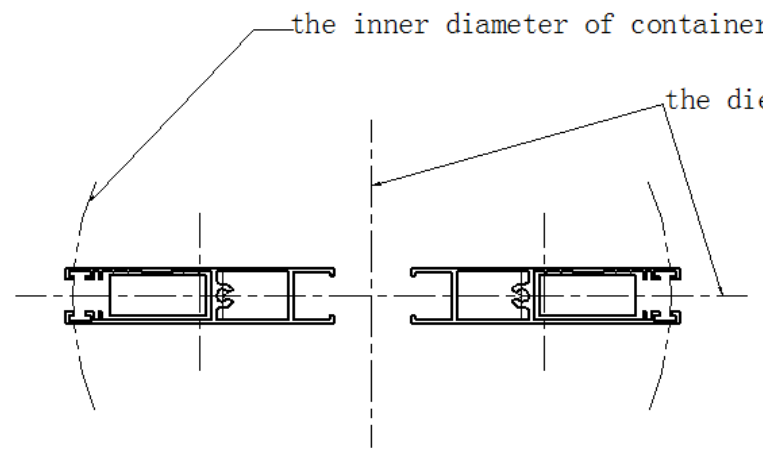

(a)

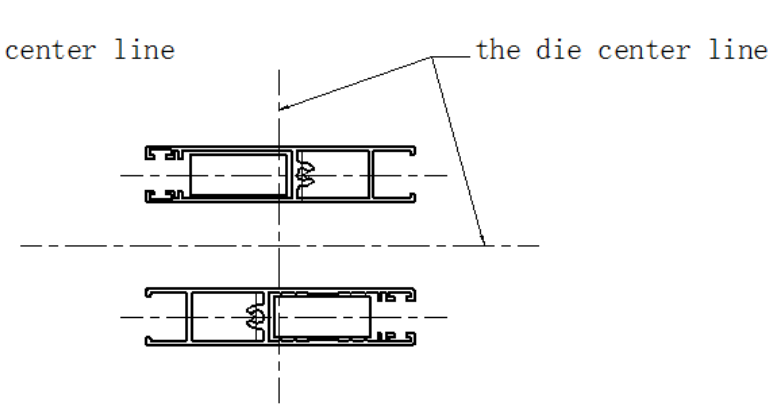

(b)

Fig.3 The signal of die holes arrangement

The layout in Figure 3 (a) is a symmetry of left and right, it has the advantages of no contacting with each other when the twin cavities are extruded,it can avoid bumps or intertwined confusion. But the disadvantage of the layout is, because of the pressure gradient across the section of the container, The layout is not conducive to the formation of the die hole close to the inner wall of the 
container, at the same time, the way of spreading must be used in the die to ensure the supply of metal for these parts near edge, which will increase the complexity of the metal flow. In addition, the shape and size of the die must be increased to ensure the strength of the die, thereby increasing the cost of the die.

The layout in Figure 3(b) is a symmetry of above and under, it can make full use of the capacity of the container, each part of the die hole is concentrated in the center region of the extrusion, which is favorable for the adjustment of the metal flow velocity, and the size of the die can be reduced.

After a comparison of these two programs, the use of the layout in figure $3(\mathrm{~b})$ is more appropriate.

\subsection{The Design of Portholes}

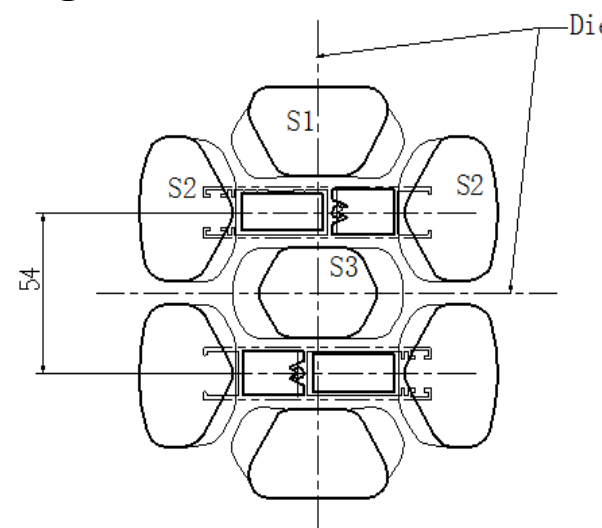

(a)

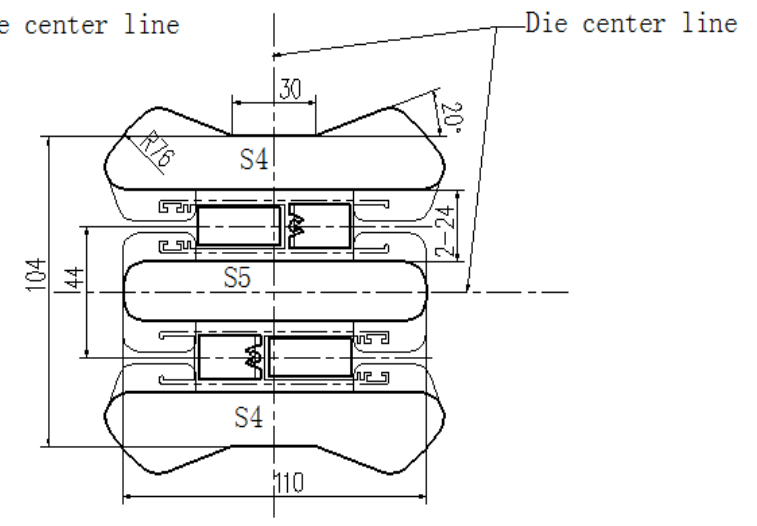

(b)

Fig.4 The arrangement of portholes

Based on the layout in Figure 3(b), the design of the portholes is carried out, according to the experience, the preliminary programs should be finished With the help of CAD software, there are two kinds of mature arrangement of portholes by experience, as shown in figure 4.

The three-dimensional models of the two schemes in figure4 are established under the environment of UG, and the models must be saved as a fixed pattern into the extrusion simulation software, the simulation and calculation and observation are carried out, and the results were compared and analyzed, and combined with the experience to make correction. Through the simulation, it is found that the metal flow of scheme in Figure 4(a) is more complex, and the flow rate is difficult to be consistent, which is difficult to adjust the area relationship between the S1and S2 and S3. In addition, the porthole S2 is corresponding to the root of the cantilever, and its change of the area will effect on the deformation of the cantilever, with numerous in quantity of portholes, the errors of manufacture will cause a very sensitive to the synchronization of the extrusion and increase the difficulty of subsequent die repair.

Comparing the layout in Figure 4(b) scheme, the quantity of portholes is less, mainly the area relationship is between the adjustment of porthole S4 and S5, when the area of porthole S5 is determined, it will be simpler and easier to adjust the area of porthole S5, the adjustment does not involve to modify or change the bridge.And the bridge can completely shield and protect the cantilever, which is more favorable for improving the strength of the die. Therefore, the use of the layout in Figure 4(b) scheme is more appropriate. Its main parameters are as follows:

(1)The feeder ratio of ports area is 12.5 , desirable extrusion ratio of 30 to 40 percent.

(2)The width of the bridge is $24 \mathrm{~mm}$.

(3)The area relationship between the porthole S4 and S5 is shown in Eq.1.

$$
\mathrm{S} 5=0.82 \mathrm{~S} 4
$$

(4)The result shows when the area relationship meets certain conditions shown in Eq.2, the flow rate of metal is easy to be consistent.

$$
\mathrm{S} 5=(0.75 \sim 0.85) \mathrm{S} 4
$$

(5)The largest circumcircle of porthole is $160 \mathrm{~mm}$.

(6)The structure of the bridge is similar to dripping of water, its feeder position is a trapezoid, which is a conical shape in the outlet part, as shown in Figure 5. 


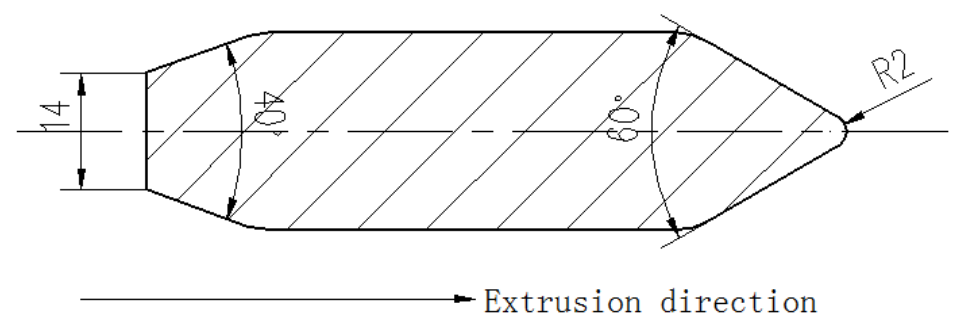

Fig. 5 The structure of the bridge

2.4 The Male Die and The Structure of the Cores. Because of a fake core in male die, the cores should be designed into different structures according to the different functions, the real core uses the frustum and the fake core with cone type, as shown in Figure 6.

2.5 The Chamber of Female Die and the Bearing. For the extrusion die with twin or multi cavities, in order to eliminate the effect of manufacturing errors on the extrusion synchronization and to avoid the rigid region of metal flow in the central part of the cavities to cause the coarse grain in the profile, the welding chamber must be designed to be independent respectively. A wall must be set between the welding chamber, its width of desirable is $6 \mathrm{~mm}$ to $8 \mathrm{~mm}$, and the height is $8 \mathrm{~mm}$ to $10 \mathrm{~mm}$. For the choice of the bearing is selected according to the single cavity.
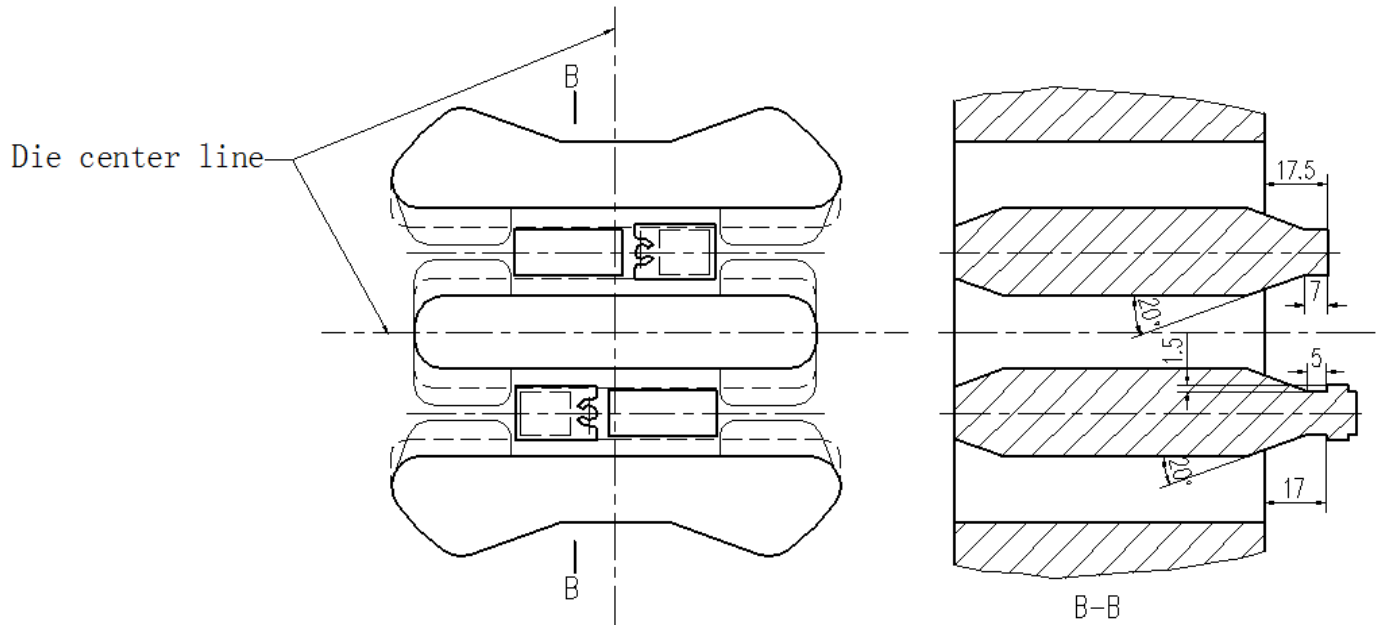

Fig. 6 The signal of the structure of cores

When one is selected, the other one is the same as it. The welding chamber and the bearing are shown in Figure 7.

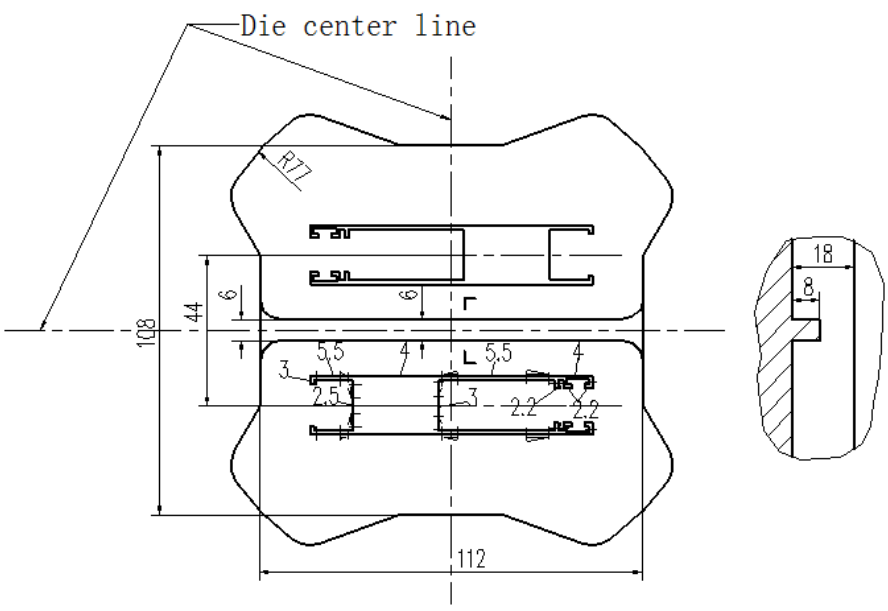

Fig.7 The signal of welding chamber and the bearing

2.6 The Die Structure Composition. The porthole die is composed of male and female die. In the extrusion process, in order to avoid the fake core bending downwards and touching the cantilever give a force to the cantilever, a stress space should be kept between the false core and the cantilever, and for processing convenience, the clearance of the space should be take in the false 
core, the clearance values is $0.5 \mathrm{~mm}$ according to the experience. The die structure is shown in figure 8 .

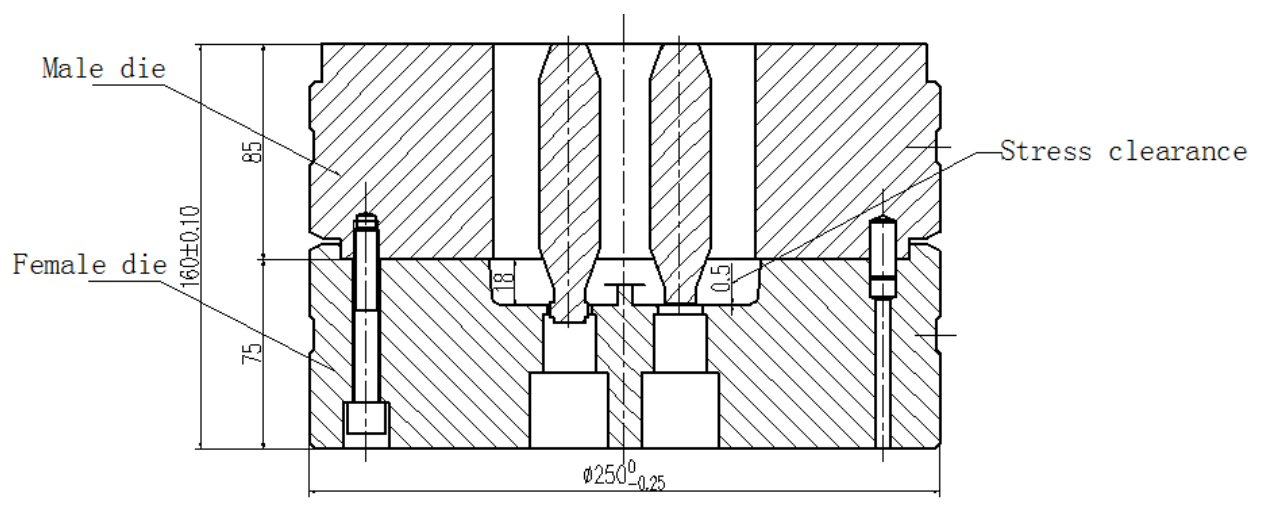

Fig. 8 The signal of die structure composition

\section{Conclusions}

When the design of porthole die, computer simulation, revise of experience and test of extrusion and use tracking are finished, the results show that the die is successful in one time. And by the repeated use after nitrided, the die extrusion production life reached 28.7 tons. Thus it can be shown that the new structure named protection type with twin cavities in a die is effective, it can improve production efficiency and reduce cost, at the same time, we can see that the die structure, core determination, arrangement of die holes, the number of portholes, and its size and its layout, the die welding chamber and the bearing are important and crucial in the new structure with twin cavities. This provides a reliable practical data for the further exploration and research of multi cavities extrusion die, in particular for the semi hollow section, and accumulates valuable experience.

\section{References}

[1] LIU Jingan. Die design,manufacture,application and maintains for aluminum profiles extrusion[M].Beijing:Metallurgical Press,1999:181 183.

[2] XIE Jianxie,LIU Jingan, Die design,manufacture,application and maintains for aluminum profiles extrusion[M].Beijing:Metallurgical Press,2012:133 138

[3] WANG Liwei.Optimization design of extrusion die for the bigger slenderness ratio half hollow aluminum profile[J].Die and Mould Manufacture,2011(4):61-64.

[4] YU Mingtao,LI Fuguo.Simulation extrusion process of the sketch hollow aluminum profile based on infinite volume method[J].Die and Technology, 2008(4):40-43.

[5] SUN Xuemei,ZHAO Guoqun.Fake porthole extrusion die structure design and strength analysis for cantilever aluminum alloy profiles[J].Journal of Mechanical Engineering,2013, 49 (24) : $39 \sim 44$.

[6]KUANG Weihua,CHEN Biaobiao.Research on design and structure of extrusion die for cantilever aluminum profile [J].Hot Working Technology,2013,42(21):136-138.

[7]DENG Rurong,Huang,Xuemei.Design of the extrusion die of semi-hollow aluminum profile[J].Light Alloy Fabrication Technology,2015,43(4):51-54.

[8]Xu Yongli, Huang Shuangjian, Pang Zugao, et al.Failure analysis of extrusion die and optimization of heat treatment process for aluminum alloy circular tube $[\mathrm{J}]$. Forging \& Stamping Technology, 2015, 40 (2) : 116-122. 
[9]Hu Dongpo, Wang Leigang, Huang Yao.Steady-state simulation and die improvement on the extrusion of prolate aluminum profile [J]. Forging \& Stamping Technology, 2015, 40 (4) : 69-73. 